Article

\title{
Ectopic Expression of Glycine max GmNAC109 Enhances Drought Tolerance and ABA Sensitivity in Arabidopsis
}

\author{
Nguyen Cao Nguyen ${ }^{1}$, Xuan Lan Thi Hoang ${ }^{1}$, Quang Thien Nguyen ${ }^{1}$, Ngo Xuan Binh ${ }^{2}$, \\ Yasuko Watanabe ${ }^{3}$, Nguyen Phuong Thao ${ }^{1, *}$ and Lam-Son Phan Tran ${ }^{4, *}$ (D) \\ 1 School of Biotechnology, International University-Vietnam National University HCMC, \\ Ho Chi Minh 700000, Vietnam; nguyencaonguyenbiotech@gmail.com (N.C.N.); \\ htlxuan@hcmiu.edu.vn (X.L.T.H.); quang.nguyen212@gmail.com (Q.T.N.) \\ 2 Faculty of Biotechnology and Food Technology, Thai Nguyen University of Agriculture and Forestry, \\ Thai Nguyen 250000, Vietnam; ngobinh2014@gmail.com \\ 3 Stress Adaptation Research Unit, RIKEN Center for Sustainable Resource Science, 1-7-22, Suehiro-cho, \\ Tsurumi, Yokohama 230-0045, Japan; yasuko.watanabe@riken.jp \\ 4 Institute of Research and Development, Duy Tan University, 03 Quang Trung, Da Nang, Vietnam; \\ Stress Adaptation Research Unit, RIKEN Center for Sustainable Resource Science, 1-7-22, Suehiro-cho, \\ Tsurumi, Yokohama 230-0045, Japan \\ * Correspondence: npthao@hcmiu.edu.vn (N.P.T.); tranplamson@duytan.edu.vn or \\ son.tran@riken.jp (L.-S.P.T.)
}

Received: 12 September 2019; Accepted: 1 November 2019; Published: 7 November 2019

\begin{abstract}
The NAC (NAM, ATAF1/2, CUC2) transcription factors are widely known for their various functions in plant development and stress tolerance. Previous studies have demonstrated that genetic engineering can be applied to enhance drought tolerance via overexpression/ectopic expression of $N A C$ genes. In the present study, the dehydration- and drought-inducible GmNAC109 from Glycine max was ectopically expressed in Arabidopsis (GmNAC109-EX) plants to study its biological functions in mediating plant adaptation to water deficit conditions. Results revealed an improved drought tolerance in the transgenic plants, which displayed greater recovery rates by $20 \%$ to $54 \%$ than did the wild-type plants. In support of this finding, GmNAC109-EX plants exhibited lower water loss rates and decreased endogenous hydrogen peroxide production in leaf tissues under drought, as well as higher sensitivity to exogenous abscisic acid (ABA) treatment at germination and early seedling development stages. In addition, analyses of antioxidant enzymes indicated that GmNAC109-EX plants possessed stronger activities of superoxide dismutase and catalase under drought stress. These results together demonstrated that GmNAC109 acts as a positive transcriptional regulator in the ABA-signaling pathway, enabling plants to cope with adverse water deficit conditions.
\end{abstract}

Keywords: ABA; Arabidopsis; drought tolerance; ectopic expression; Glycine max; GmNAC109

\section{Introduction}

As the world's population continues to grow rapidly, there has been a great demand for improved crop productivity to maintain global food security. Unfortunately, biotic and abiotic stresses have been putting significant pressure on crop growers [1,2]. Having been defined as adverse non-living environmental conditions, abiotic stresses-including drought, salinity, flooding and extreme temperatures-negatively influence the survival and productivity of crop plants [3]. Amongst the abiotic stressors, drought is believed to be the most threatening factor, posing great challenges to crop production and quality across the globe [4]. Drought, which can last for months, or years in the 
worst cases, may happen due to the shortages of rainfall or water in soil [5]. Prolonged water scarcity can lead to major physiological and developmental changes, causing impairment in plant development or even lethality [6]. For example, it has been shown that when plants are being exposed to drought, stomatal closure is induced which results in a reduction in photosynthetic activities [7]. Although drought-related phenotypic traits (e.g., root and shoot traits) of plants are often used to evaluate their resistance to drought, studies on molecular mechanisms employed by plants to react to drought have emerged as enormously important research topics [8-11]. It has been reported that the expression of many genes, including both functional and regulatory ones, is greatly altered when plants are exposed to water deficit conditions [12]. Gaining knowledge on the functions of drought-responsive genes would provide critical information for developing novel cultivars with improved drought tolerance by genetic engineering [13-15].

Being able to regulate gene expression, transcription factors (TFs) have been known to be indispensable players in the regulation of plant drought responses [16,17]. Among the drought-related TF families in plants, the NAC (NAM-No Apical Meristem of petunia, ATAF1/2-Arabidopsis Transcription-Activating Factor1/2, and CUC2-Cup-Shaped Cotyledon2) family has been identified as a key plant-specific TF family [18-21]. The NAC proteins are characterized by the possession of a conserved DNA-binding domain at the $\mathrm{N}$-terminus and a transcriptional regulatory domain at the C-terminus [22]. In addition, a considerable number of NAC genes from various plant species have been evidenced to play imperative roles in mediating plant adaptation to drought [12,21]. For instance, transgenic Arabidopsis plants ectopically expressing Cicer arietinum CarNAC2 [23] or Suaeda liaotungensis SINAC8 [24] display improved drought resistance. In rice (Oryza sativa), the drought tolerance can be enhanced by overexpressing the OsNAC5 gene [25], or ectopically expressing the Eleusine coracana EcNAC67 gene [26]. Applications of the NAC genes for improving drought resistance have been reported in many other crops as well, including tomato (Solanum lycopersicum) $[27,28]$, banana (Musa acuminata) [29], cotton (Gossypium hirsutum) [30], and wheat (Triticum aestivum) [31,32].

In soybean (Glycine max), efforts have also been made to functionally characterize drought-related GmNAC genes. Amid more than $30 \mathrm{GmNACs}$ identified as drought- and/or dehydration-inducible genes [14,15,33-35], only a few genes have been characterized using in planta studies for their regulatory roles in mediating plant tolerance to water stress. For example, investigations have been undertaken on GmNAC003, GmNAC004 [20], GmNAC085 [36,37], and GmSNAC49 (Glycine max stress-inducible NAC49) [38] in plant responses to the conditions of adverse water deficit. By performing a transcription activation assay in yeast, GmNAC109 was shown to possess an activation domain, which can act as a gene expression activator [35]. In addition, GmNAC109 was proposed as a candidate for improvement of crops, in terms of drought tolerance, by using genetic engineering as its expression level was found to have a positive correlation with the drought-tolerant phenotype of soybean [14]. Previous studies also revealed that GmNAC109 expression was up-regulated in the root tissues of soybean under both dehydration [33,35] and drought conditions [14]. Therefore, in the present study, we studied the drought-mediated actions of GmNAC109 in conferring drought resistance by analyzing the performance of Arabidopsis plants ectopically expressing GmNAC109 (GmNAC109-EX) under drought and abscisic acid (ABA) treatments in terms of phenotypic, physiological, biochemical, and molecular aspects.

\section{Materials and Methods}

\subsection{Generation of Transgenic Arabidopsis GmNAC109-EX Plants}

The complete open reading frame of GmNAC109 (Glyma14g24220.1 in [33], or the so-called GmNAC012 in [35]) was inserted downstream of the constitutive CaMV 355 promoter in the vector pGHX that has the pGreen plasmid backbone [39]. All the cloning procedures were performed as previously described [37,40], and a hygromycin selection marker was employed for the selection of transgenic plants instead of a kanamycin one. The recombinant vector was transferred into 
Agrobacterium followed by transformation of Arabidopsis (Col-0) using the floral dip method [41]. Screening of independent homozygous progenies of GmNAC109-EX lines was achieved by following the Mendelian genetic laws, which are based on the ratios of hygromycin-resistant and -sensitive phenotypes over three successive $\mathrm{T}_{1}$ to $\mathrm{T}_{3}$ generations [42]. Expression of the transgene GmNAC109 was examined by RT-qPCR using the GmNAC109-specific primers and Actin2 as the house-keeping gene (Supplementary Table S1).

\subsection{Plant Growth Conditions}

The seeds were surface-sterilized and germinated on Murashige and Skoog (MS) plates (1\% sucrose, $0.8 \%$ agar) [43]. In brief, the collected seeds were sterilized by ethanol $(70 \% v / v)$ for $1 \mathrm{~min}$ and sodium hypochlorite $(2 \% v / v)$ for $15 \mathrm{~min}$, followed by rinsing with sterile distilled water to remove the chemical residues. The decontaminated seeds were sowed on MS plates, which were then kept under dark conditions for $48 \mathrm{~h}$ at $4{ }^{\circ} \mathrm{C}$ for stratification, and subsequently under normal growth conditions $\left(22{ }^{\circ} \mathrm{C}\right.$, humidity $60 \%$, 16-h-light/8-h-dark photoperiod, $70 \mu \mathrm{mol} \mathrm{m}^{-2} \mathrm{~s}^{-1}$ ) for 14 days until used for further purposes.

\subsection{Growth Assessment of Transgenic Arabidopsis Plants under Normal Conditions}

Fourteen-day-old seedlings were transplanted from MS plates to soil (Tribat, Saigon Xanh Biotechnology Ltd. Company, Ho Chi Minh City, Vietnam) and irrigated under normal growth conditions (described in Section 2.2) for 14 days. For evaluation of root length, the plants were taken out of soil for measuring the root length. The maximum rosette radius was measured based on the length of the longest leaf of individual plant [37], using Image-J software (https://imagej.nih.gov/ij/). Measuring the whole area of Arabidopsis rosettes was performed following the procedure described in a previous study [44] using PhotoshopCC 2019 (Adobe, San José, CA, USA). The experiments were conducted in three biological replicates for each genotype, with 5 plants per replicate.

\subsection{Drought Tolerance Assay}

Fourteen-day-old seedlings were transplanted from MS plates to soil. Subsequently, the plants were grown under the growth conditions described in Section 2.2 with normal irrigation for 14 days, before the watering was suspended for 12 days when the relative soil moisture content dropped to approximately 18\% [45]. After the drought treatment, irrigation was re-applied for 3 days, and the survival rate of each genotype was then evaluated [46]. Relative soil water content was monitored over the studied drought period by using a Moisture Meter (TK-100G, Yieryi, Guangdong, China). The experiments were conducted in three biological replicates for each genotype, with 10 plants per replicate.

\subsection{Water Loss Rate Determination}

For determination of water loss rate (WLR), leaves were removed from the 28-day-old plants that were grown on MS plates for 14 days and then soil for an additional period of 14 days, as described in Section 2.3. The fresh weight (FW) of individual leaves was immediately recorded using an analytical balance (Sartorius, no. 68285437, Göttingen, Germany). These leaves were then left to air-dry on a laboratory bench for a period of $5 \mathrm{~h}$. While being air-dried, the leaves were weighed every $30 \mathrm{~min}$ to determine the water loss rates over the treated time period using FW reduction [47]. The experiment was conducted using nine replicates for each genotype, with two largest leaves per plant for each replicate.

\subsection{Assays for Endogenous Hydrogen Peroxide and ROS-Scavenging Enzyme Activities}

The plant materials for these assays were collected on day 12 of the drought treatment (Section 2.4). All experiments were conducted in three biological replicates for each genotype. To measure the 
hydrogen peroxide $\left(\mathrm{H}_{2} \mathrm{O}_{2}\right)$ content, $\mathrm{H}_{2} \mathrm{O}_{2}$ was extracted from the harvested leaves using the previously described method with minor modifications [48]. Briefly, $0.2 \mathrm{~g}$ of the leaf tissues, which was used as one replicate sample, was homogenized in the phosphate-buffered saline (PBS) solution $(1.8 \mathrm{~mL}, 0.1 \mathrm{M}$, $\mathrm{pH}$ 7.4). After centrifugation $\left(10,000 \mathrm{rpm}, 10 \mathrm{~min}, 4^{\circ} \mathrm{C}\right)$ of the tissue homogenate, a mixture containing the supernatant $(1 \mathrm{~mL})$ and reaction solution $(1 \mathrm{~mL}$ of $0.1 \%$ titanium(III) sulfate and $20 \%$ sulfuric acid) was prepared for the spectrophotometric measurement at $410 \mathrm{~nm}$. A standard curve was established to determine the $\mathrm{H}_{2} \mathrm{O}_{2}$ concentrations in the samples.

To determine antioxidant enzyme activities, the leaf tissues ( $0.2 \mathrm{~g}$ tissue per sample) were homogenized in $2 \mathrm{~mL}$ cold potassium phosphate buffer ( $1 \mathrm{M}, \mathrm{pH} 7.8$ ) containing EDTA $0.1 \mathrm{M}$ and $2 \%$ polyvinylpyrrolidone (molecular weight of 8000 ). The supernatant obtained after centrifugation was used to quantify total soluble protein content using the Bradford method [49]. Bovine serum albumin (Sigma, Saint Louis, MO, USA) was used to establish the standard curve. Activities of enzymes superoxide dismutase and catalase were measured following the procedures described in previous studies [50,51].

\subsection{Expression Analysis of Antioxidant Enzyme-Encoding Genes}

Plants that were grown 14 days on MS plates and then 7 days in soil pots were used for the dehydration treatment. The whole plant samples were collected at various time points $(0,5$, and $8 \mathrm{~h})$ during the dehydration period for total RNA isolation. Methods for RNA extraction, first-strand cDNA synthesis, and RT-qPCR were previously described [14]. Information of primers used for RT-qPCR reactions is provided in Supplementary Table S1. Relative expression levels were determined following the $2^{-\Delta \Delta C t}$ method [52], with Actin2 being used as the house-keeping gene. The experiment was performed using three biological replicates per genotype for each time point of sample collection.

\subsection{ABA Sensitivity Assay}

Effects of exogenous ABA on seed germination and early seedling development were evaluated by sowing the seeds on MS medium ( $1 \%$ sucrose, $0.8 \%$ agar) supplemented with various $\mathrm{ABA}$ concentrations $(0,0.3$, and $0.5 \mu \mathrm{M})$ and incubating the plates under normal growth conditions as specified in Section 2.2. The assays were perfomed following the method described in Huang et al. [53]. For germination assay, after 2 days of stratification, the plates were incubated under normal growth conditions for 3 days, and germination rates were then recorded based on the emergence of the seed radicles, as observed under a magnifying glass $(10 \times)$. The green cotyledon rates were determined after 7 days of incubation under normal growth conditions based on the appearance of green cotyledons in each seedling. Each experiment was conducted in three replicates for each genotype, with 100 seeds per replicate.

\subsection{Statistical Analysis}

The data were analyzed by using the Student's $t$-test (significant differences with $p$-value $<0.05$ were indicated by asterisks) for comparison between WT and each EX line, or one-way ANOVA using SPSS software (significant differences with $p$-value $<0.05$ were indicated by different letters according to Duncan's multiple range test) for comparison among all genotypes.

\section{Results}

\subsection{Reduced Growth Phenotype of GmNAC109-EX Lines under Normal Conditions}

To explore the biological functions of GmNAC109, we introduced the complete coding sequence of this gene into the model plant Arabidopsis under the control of the constitutive promoter CaMV 35S. Three independent homozygous GmNAC109-EX lines (EX1, EX2, and EX3) that were successfully identified were firstly examined for the transgene expression and phenotypic characteristics (Figure 1). As expected, RT-qPCR using the GmNAC109-specific primers detected the expression of GmNAC109 in 
all three EX lines but not in the WT plants, and the gene expression levels were comparable among the EX lines (Figure 1a). In comparison with WT, all three EX lines displayed smaller shoot-related phenotypes under normal growth conditions. As shown in Figure 1b, rosette-related traits, including their radius and area, were significantly reduced in the GmNAC109-EX plants. Additionally, the average primary root lengths of 4-week-old transgenic plants were ca. 2 -cm shorter than that of WT (Figure 1c).

b
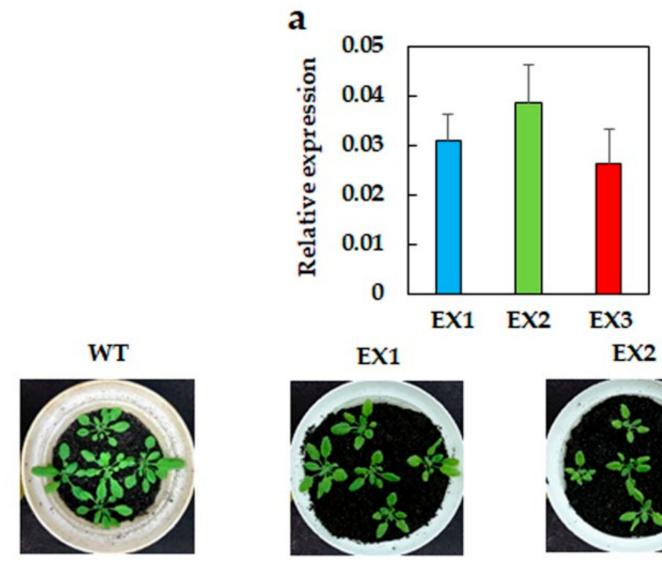

EX1

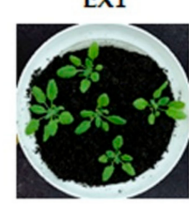

EX2
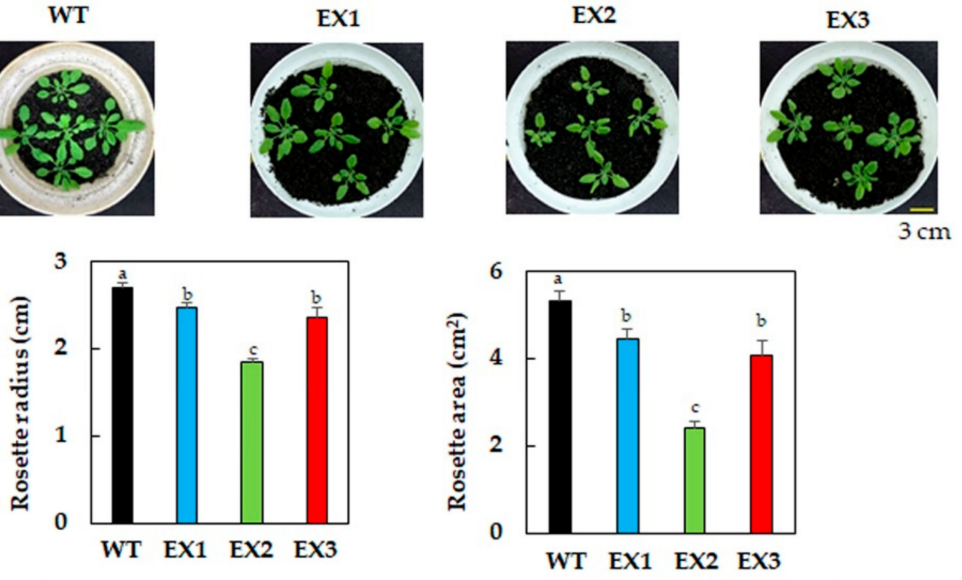

C

WT

EX1
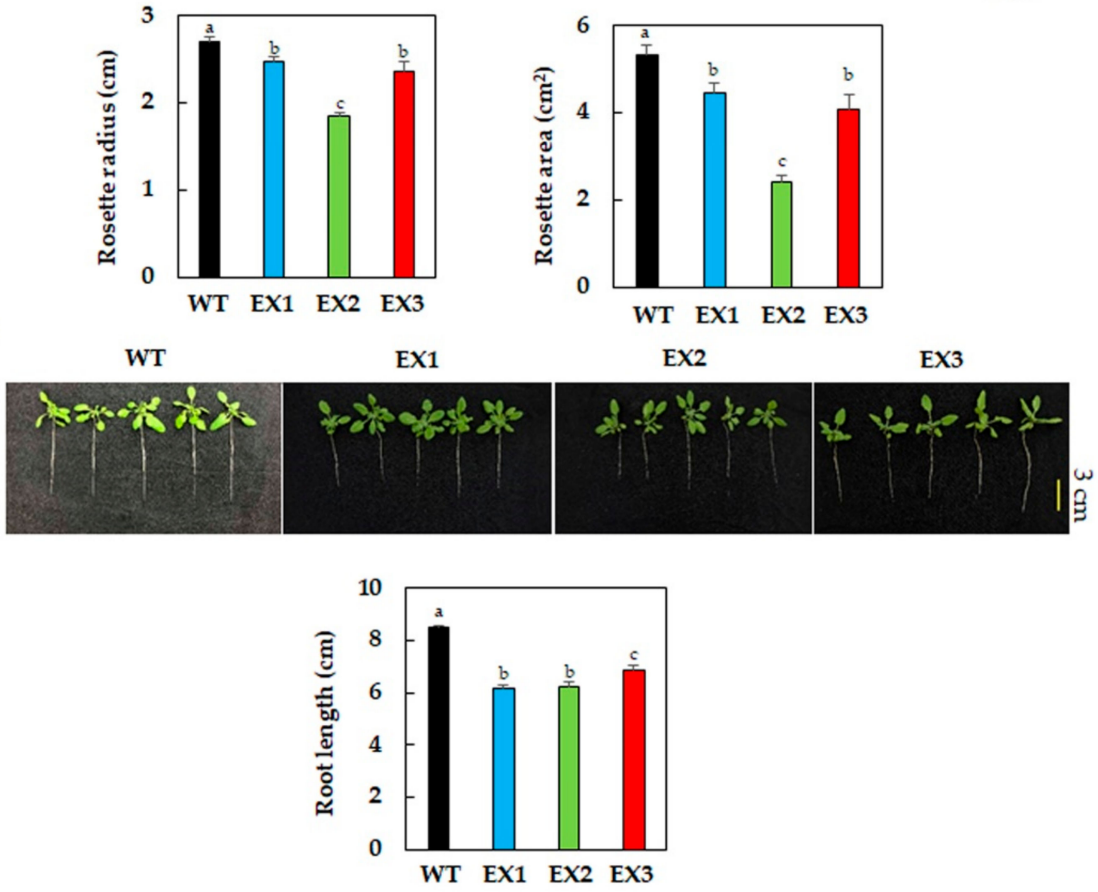

Figure 1. Transgene expression in the 28-day-old GmNAC109-EX1, 2, and 3 lines, and their phenotype under normal growth conditions. (a) Relative expression of the GmNAC109 in the EX lines $(n=3$ biological replicates/genotype). (b) Representative photographs, maximum rosette radius and average rosette area of 28-day-old EX lines ( $n=3$ replicates/genotype; 5 plants/replicate). (c) Representative photographs and average primary root length ( $n=3$ replicates/genotype; 5 plants/replicate). Standard errors were calculated and shown by error bars. Duncan's multiple range test was used for statistical analysis, and significant differences among the genotypes were indicated by different letters ( $p$-value $<0.05)$.

\subsection{Improved Tolerance of GmNAC109-EX Plants to Drought}

The drought tolerance assay was conducted to assess the ultimate benefit brought by ectopic expression of GmNAC109 in Arabidopsis plants. Results revealed that after 12 days of non-irrigation (i.e., 
when the relative soil moisture content dropped from $72 \%$ to ca. $18 \%$ ) followed by 3-day re-watering, differential recovery rates were observed between GmNAC109-EX and WT plants (Figure 2a-c). More specifically, the GmNAC109-EX lines survived better than WT ( $43 \%$ of EX1, 77\% of EX2, 50\% of EX3, and only $23 \%$ of the WT plants) (Figure 2c). Next, the evaluation of the transpiration rates in individual leaf samples was undertaken using a dehydration-based method. We noted that the detached leaves dehydrated at bench showed a gradual reduction in their weight over the 5-h-dehydration (Figure 2d), indicating that they gradually lost water during the treatment. At the same time points of examination, the WT leaves suffered water loss at a higher rate than did the leaves of GmNAC109-EX plants. Specifically, during early dehydration treatment (0.5-1.5 h), excised WT leaves lost water faster than leaves of all three EX lines, while under prolonged dehydration conditions $(2-5 \mathrm{~h})$ they lost more water than the leaves of EX2 and EX3 lines (Figure 2d). These results imply that the GmNAC109-EX plants have better water retention under adverse water deficit conditions.
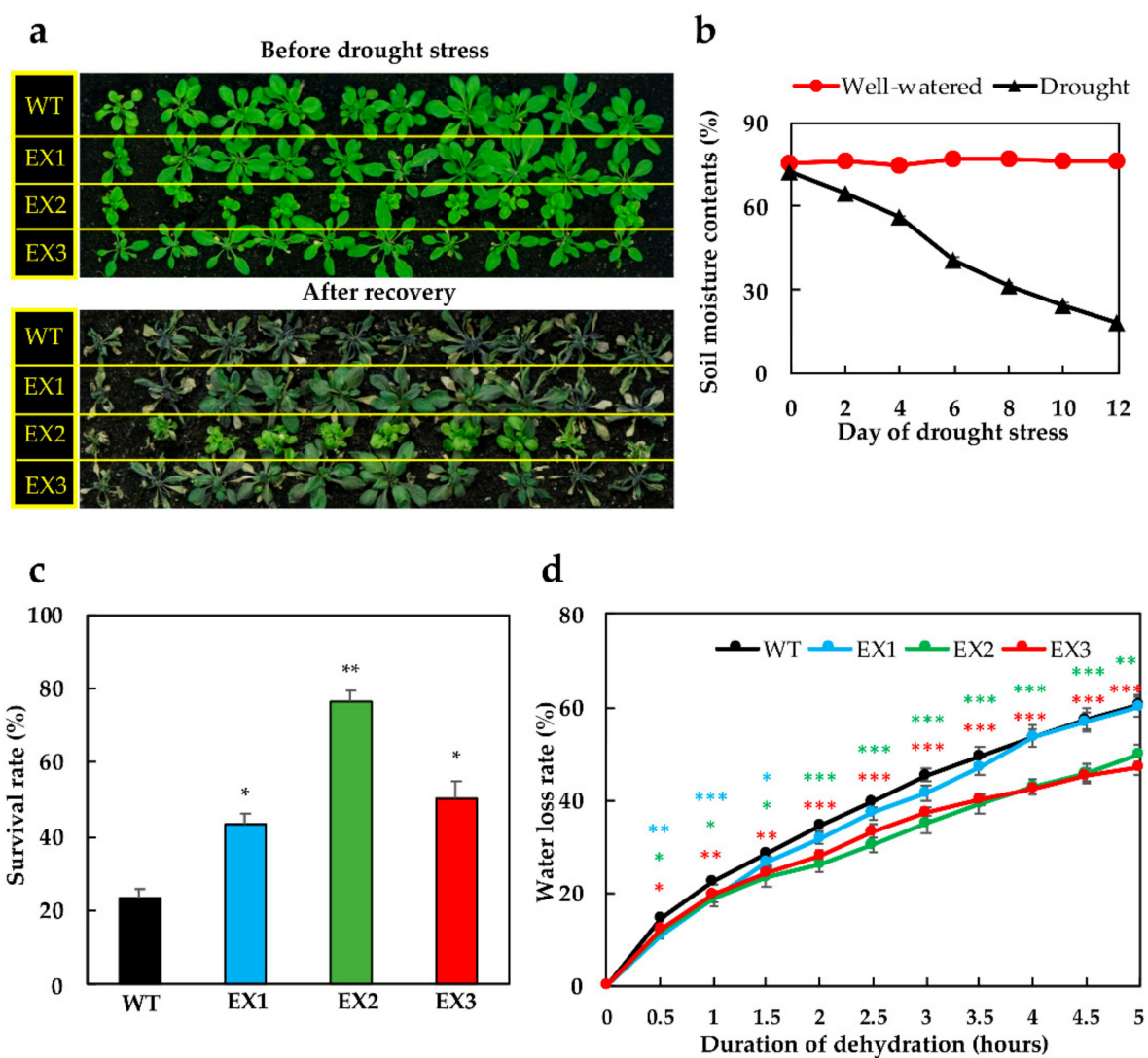

Figure 2. Examinations of drought survival rates and water loss rates of the GmNAC109-EX1, 2, and 3 lines. (a) Phenotypes of wild-type (WT) and EX lines before the drought treatment (i.e., 28-day-old) and after the recovery period (i.e., 43-day-old plants; 12-day-non-irrigation followed by 3-day re-watering). (b) Monitored relative soil moisture contents during the drought treatment are shown ( $n=6$ readings/time point). (c) Recorded survival rates of WT and EX plants after re-watering $(n$ $=3$ replicates/genotype; 10 plants/replicate). (d) Average water loss rates of leaves detached from 28-day old plants and left air-dehydrated over a 5-h duration ( $n=9$ replicates/genotype; 2 leaves/plant/replicate). Standard errors were calculated and shown by error bars. Asterisks indicate significant differences, as determined by a Student's $t$-test, between each EX line and the WT $\left({ }^{*} p\right.$-value $<0.05$; ${ }^{* *} p$-value $<0.01$; *** $p$-value $<0.001)$.

\subsection{ABA Hypersensitivity of GmNAC109-EX Lines}

Phytohormones, particularly abscisic acid (ABA), have been known to participate in regulating plant acclimation to drought [54]. Therefore, we tested the effects of exogenous ABA application on the germination rate and seeding development (cotyledon greening) to find out if GmNAC109 belongs 
to the ABA-mediated signaling pathway in regulation of plant drought responses. As the EX2 line displayed a significantly smaller rosette in comparison with that of other two EX lines, we excluded this line from the ABA assay and subsequent experiments. Results of the germination assay revealed that on the ABA-free MS plates, WT and two examined EX lines shared similar germination rates (approximately 89\%). However, an inhibitory effect of ABA on seed germination was observed as the proportions of seeds that could germinate were reduced markedly (Figure 3a). Comparing the germination rates between WT and the EX lines revealed that under the same ABA concentrations, the decline in germination rates was more pronounced in the EX plants. According to our data, WT seed germination dropped by $10 \%$ and $16 \%$ by 0.3 and $0.5 \mu \mathrm{M}$ ABA application, respectively, whereas the corresponding values were $39 \%$ and $54 \%$ in EX1, and $45 \%$ and $55 \%$ in EX3. Consistently, the results of examination of the ABA effects on green cotyledon also showed stronger ABA-responsiveness of the GmNAC109-EX lines. As shown in Figure 3b, the proportion of WT seedlings that could display green cotyledons was more than double of that obtained from EX1 and EX3 seedlings at the same exogenous ABA concentrations.
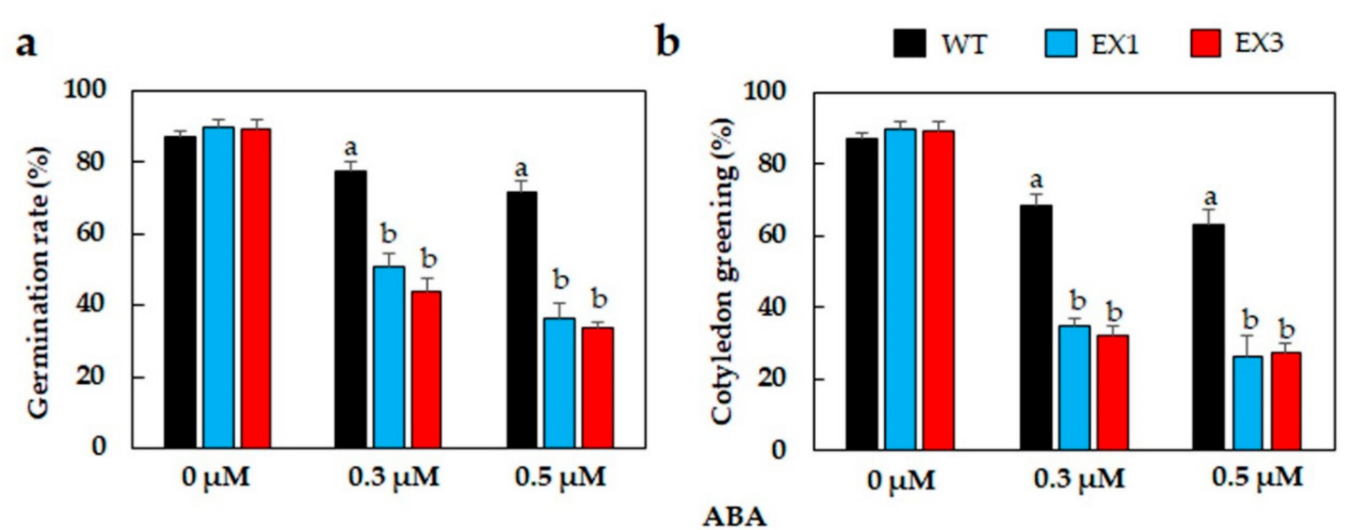

Figure 3. ABA sensitivity assay to examine ABA effects on seed germination and cotyledon greening of the GmNAC109-EX1 and 3 lines. (a) Germination rates of seeds on MS medium supplemented with 0, 0.3, and $0.5 \mu \mathrm{M}$ ABA after 3 days of incubation under normal growth conditions $(n=3$ replicates/genotype; 100 seeds/replicate). (b) Cotyledon greening rates at different ABA concentrations after 7 days of incubation under normal growth conditions ( $n=3$ replicates/genotype; 100 seeds/replicate). Standard errors were calculated and shown by error bars. Duncan's multiple range test was used for statistical analysis of the data received from all genotypes within the same treatment, and significant differences among the genotypes were indicated by different letters ( $p$-value $<0.05$ ).

\subsection{Enhanced Antioxidant Enzyme Activities in the GmNAC109-EX Lines}

Plant damage by oxidative stress is usually induced under extended drought conditions, which is featured by the accumulation of endogenous reactive oxygen species (ROS), such as hydrogen peroxide $\left(\mathrm{H}_{2} \mathrm{O}_{2}\right)$ [55]. Therefore, we next investigated the accumulation levels of cellular $\mathrm{H}_{2} \mathrm{O}_{2}$ contents in the leaf tissues of plants growing under normal and drought conditions. Our data showed that under irrigation conditions, the healthy plants exhibited comparable $\mathrm{H}_{2} \mathrm{O}_{2}$ levels in the WT and EX lines (Figure $4 \mathrm{a}, \mathrm{b}$ ). The $\mathrm{H}_{2} \mathrm{O}_{2}$ concentrations showed increases in the stress-treated leaf samples by 5.4-fold, 3.3-fold, and 4.1-fold in WT, EX1, and EX3 lines, respectively (Figure 4a,b). This differential stress-induced $\mathrm{H}_{2} \mathrm{O}_{2}$ production resulted in a lower $\mathrm{H}_{2} \mathrm{O}_{2}$ excess in the EX plants, suggesting a less serious oxidative stress impact on EX plants in comparison with WT. 

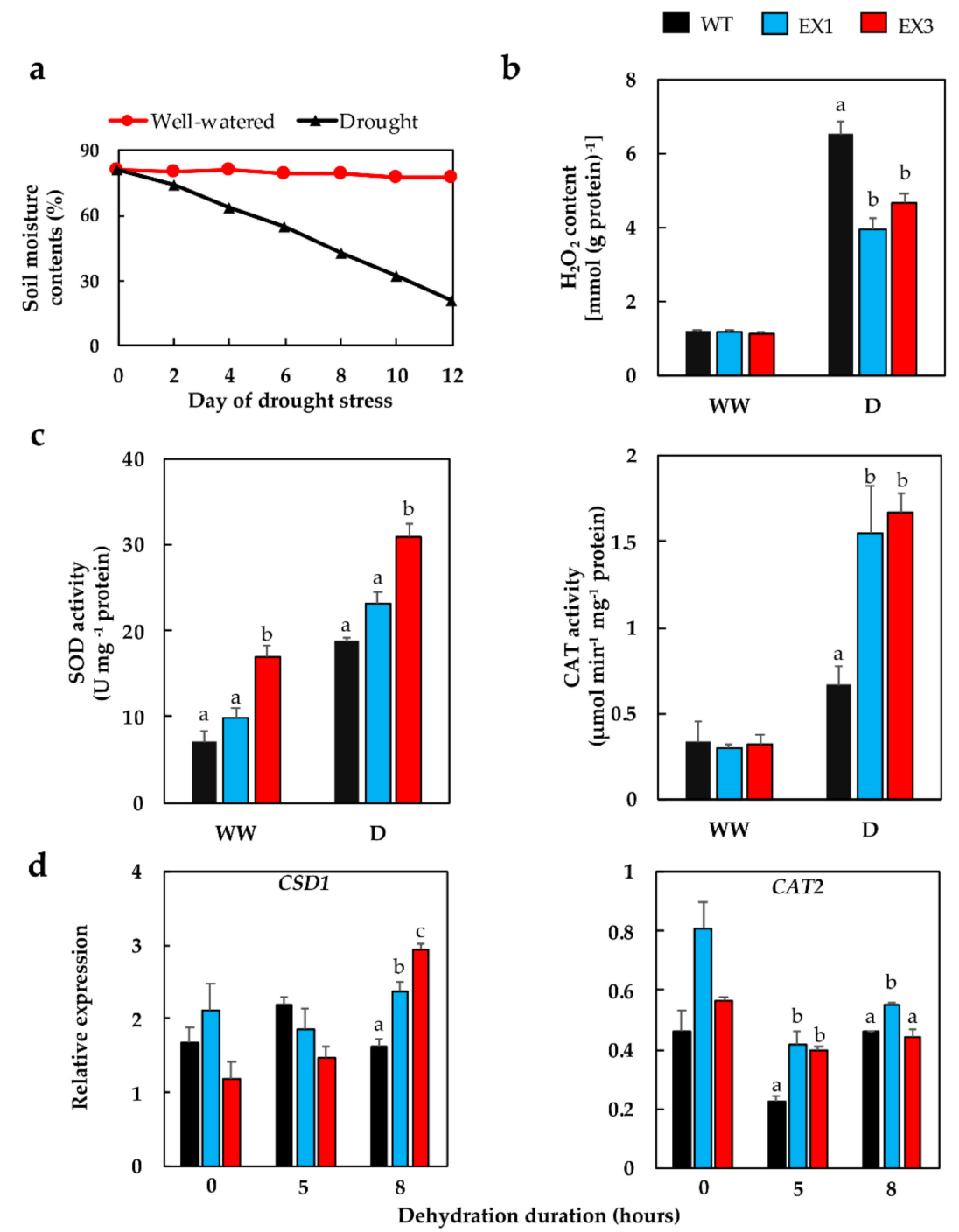

Figure 4. Drought-induced oxidative stress-related analyses in GmNAC109-EX1 and 3 lines. (a) Relative soil moisture contents were measured over the 12-day-drought duration $(n=6$ readings/time point). (b) Hydrogen peroxide $\left(\mathrm{H}_{2} \mathrm{O}_{2}\right)$ content in leaf tissues of 40-day-old plants that had been grown under a well-watered (WW) condition or exposed to a 12-day drought (D) $(n=3$ biological replicates/genotype/treatment). (c) Antioxidant activities of superoxide dismutase (SOD) and catalase (CAT) enzymes in leaves of 40-day-old plants that had been grown under a well-watered (WW) condition or exposed to a 12-day drought (D) period ( $n=3$ biological replicates/genotype/treatment). (d) Relative expression of CSD1 (copper/zinc superoxide dismutase 1) and CAT2 (catalase 2) genes in 21-day-old plants that were subjected to $0-, 5-$, and 8-h dehydration treatment ( $n=3$ biological replicates/genotype). Standard errors were calculated and shown by error bars. Duncan's multiple range test was used for statistical analysis of the data received from all genotypes within the same treatment, and significant differences among the genotypes were indicated by different letters ( $p$-value $<0.05$ ).

To cope with water deficit-induced oxidative damage, antioxidant defense is activated in plants to detoxify excessive ROS [36,37]. Therefore, we proceeded to analyze the activities of superoxide dismutase (SOD) and catalase (CAT), the two ROS-scavenging enzymes that are well known to be involved in plant acclimation to water stress [56,57], to further estimate the antioxidant defense capacity of GmNAC109-EX plants under drought. Under water deficit, the SOD activity in EX3 was approximately 1.6-fold higher than that in WT, whereas the CAT activities in both EX lines were increased by more than 2-fold compared with the corresponding activity found in the WT (Figure 4c). Additional examination of the expression patterns of copper/zinc superoxide dismutase 1 (CSD1, encoding 
a SOD enzyme) and Catalase 2 (CAT2, encoding a catalase enzyme) genes under dehydration conditions showed that CSD1 expression was induced at a much higher level in the EX lines (by 1.5-1.8-fold) than in WT plants after 8-h dehydration (Figure 4d). Meanwhile, the differential expression levels in CAT2 between the EX lines (1.8-1.9-fold higher) and WT were recognized at earlier stage of dehydration ( $5 \mathrm{~h})$ (Figure $4 \mathrm{~d}$ ).

\section{Discussion}

GmNAC109 has been highlighted as an important dehydration- and drought-inducible gene, as its expression has been found to be associated with drought tolerance in soybean $[14,33,35]$. Furthermore, comparative sequence analyses of soybean NACs with Arabidopsis and rice NACs depicted that GmNAC109 TF has a putative nuclear localization signal, while the yeast hybrid assay indicated this protein possesses transactivation capacity [35]. In this study, Arabidopsis plants ectopically expressing GmNAC109 displayed remarkably improved tolerance to drought, with higher survival rates after a 12-day-drought imposition in comparison with the WT (Figure 2a-c). Enhancement of drought tolerance in transgenic plants by overexpressing/ectopically expressing $N A C$ genes has been well documented in many previous studies, such as those that used tomato SINAC3 [58], rice SNAC1 [59], SNAC3 [8] and ONAC022 [60], pumpkin (Cucurbita moschata) CmNAC1 [61], and soybean GmNAC085 [36,37] and GmNACS49 [38]. Such transgenic studies have also revealed diverse mechanisms of the NAC TFs in contributing to the enhanced drought tolerance of the transgenic plants. The advantageously modified characteristics achieved by NAC overexpression/ectopic expression include faster ROS detoxification by enhanced enzymatic activities of SOD, CAT, ascorbate peroxidase, glutathione peroxidase, glutathione $S$-transferase and glyoxalases [36,37,62-64], more developed root systems [26,65], better cellular water reservation [37,66], and/or increased accumulation of proline and sugar contents [24,67].

It is worth noting that the ectopic expression of GmNAC109 by using the CaMV 35S promoter led to the growth penalty in the GmNAC109-EX plants, especially smaller phenotypes of both shoot and root organs than what were observed in the WT (Figure 1). This observation is in accordance with the phenotypic appearance of Arabidopsis plants ectopically expressing GmNAC085, in which the transgene was also driven by the $35 S$ promoter [37]. In the present study, the GmNAC109-EX plants showed lower water loss rates than did the WT plants (Figure 2d), suggesting that the transgenic plants might evaporate less water from their smaller rosette (Figure 1b); and therefore, they were more tolerant to drought than WT plants. Such growth adjustment for better drought survival by saving limitedly available water amount was also observed in many transgenic plants, such as those overexpressing/ectopically overexpressing the Arabidopsis cytokinin oxidase/dehydrogenase (CKX) genes involved in cytokinin catabolism [68-70]. Importantly, the transgenic Arabidopsis plants carrying the construct RD29A:GmNAC085, in which the stress-inducible $R D 29 A$ promoter was used to drive the ectopic expression of GmNAC085, displayed normal development, as well as a significant level of drought tolerance, when compared with that of WT plants [36]. Therefore, using an alternative promoter such as a stress-inducible promoter is likely to improve plant drought tolerance without compromising plant growth and development.

It has been known that NAC TFs regulate various plant developmental processes, as well as plant responses to both biotic and abiotic stress factors [71-74]. In regulating plant adaptation to drought, the NAC members participate in both ABA-dependent [75-77] and ABA-independent [78] pathways. From a previous study, GmNAC109 would appear to function in an ABA-independent manner as GmNAC109 transcription was not altered upon exogenous ABA treatment [35]. In the current study, the findings obtained from the assays for ABA responsiveness revealed that the GmNAC109-EX lines showed ABA hypersensitivity on media supplied with various concentrations of ABA in an ABA dose-dependent manner (Figure 3). Analysis of the promoter region of GmNAC109 conducted in our previously published study indicated that the GmNAC109 promoter has multiple cis-acting elements, including an ABA-responsive element 2 (ABRE2, containing the core sequence "ACGTGG/TC"), a dehydration-responsive element (DRE, containing the core sequence "A/GCCGAC") and two G-box 
elements (core sequence "CACGTG") [14]. It has been known that ABA-responsive regulation may require a combination of $\mathrm{ABRE}$ and its partner [79]. Cis-regulatory elements that have been identified to couple with ABRE in facilitating ABA-mediated transcription include CE1 (coupling element 1), CE3, another ABRE element, or DRE [79-81]. In addition, DREs detected in the promoter regions of many drought-responsive genes have been found to function in ABA-independent regulatory system $[78,82]$. These data collectively imply that GmNAC109 activity might be governed by not only ABA-dependent but also ABA-independent signaling pathways in regulating plant responses to limited water conditions. In addition, the enhanced ABA responsiveness of the GmNAC109-EX plants (Figure 3) and their better ability to retain cellular water (Figure 2d) suggest the possible involvement of GmNAC109 in coordination with ABA to regulate the transpiration process in plants. ABA is the key phytohormone that controls the stomatal activities [79]. As drought progresses, endogenous ABA content is increased, even up to 30-fold [83,84], to facilitate the closure of stomatal aperture, thereby preventing water loss by transpiration [66]. Therefore, detailed functional analysis of GmNAC109 in stomatal movement is an interesting topic for future studies.

One of drought's negative impacts is the over-production of endogenous ROS, as ROS at high levels are harmful to cellular structure and metabolism [55,85]. A study in wheat conducted under drought showed that around $70 \%$ of generated $\mathrm{H}_{2} \mathrm{O}_{2}$ came from photorespiration, a triggered activity due to the closure of stomata and intensive sunlight exposure [86]. Thus, $\mathrm{H}_{2} \mathrm{O}_{2}$ levels are usually measured in drought tolerance studies, and used as an indicative parameter for evaluating the oxidative damage in plants under limited water conditions [36]. In our study, lower $\mathrm{H}_{2} \mathrm{O}_{2}$ contents in drought-treated EX plants were observed (Figure $4 \mathrm{~b}$ ), which might be attributed to the higher CAT activities detected in the EX lines in comparison with WT plants under drought (Figure 4c). As SOD provide the first layer of antioxidant defense by dismutating superoxide radicals, the observation of enhanced SOD activities in the EX lines, when compared with that of WT plants, suggests the more pronounced protection of the EX lines from oxidative stress (Figure 4c) $[85,87,88]$. Furthermore, the higher degree of induction in CSD1 and CAT2 expression under dehydration conditions in the GmNAC109-EX lines compared with that of WT indicates a positive relationship between the enzyme activities and gene expression levels under water deficit conditions (Figure 4c,d). On the other hand, under well-watered conditions, the activity of SOD of EX3 line was higher than that of the WT, whereas the expression profile of CSD1 was not significantly different between the two genotypes (Figure 4c,d). No direct correlation between CAT activities and CAT2 expression was observed either under stress conditions, where the enzyme activities were enhanced yet CAT2 expression was down-regulated in all genotypes (but still higher in EX versus WT plants) (Figure 4c,d). The reason could be that the expression of only one gene coding for an enzyme isoform was examined in our study, while there are more than one isoforms of these antioxidant enzymes, and the activity of a given enzyme is the sum of activities of its different isoforms [89]. Therefore, a comprehensive expression analysis of all members of the SOD and CAT gene families in the context of GmNAC109 ectopic expression will be an interesting future study. In addition to GmNAC109, previous analyses also demonstrated that the CSD1 and CAT2 genes are under the regulation of other NAC proteins $[37,90,91]$, inferring that NAC TFs are widely involved in modulation of antioxidant defense in response to stresses. Hence, ectopic expression of GmNAC109 in Arabidopsis is able to alleviate the drought-induced oxidative damage in transgenic plants by boosting activities of ROS-scavenging enzymes, suggesting that GmNAC109 is involved in improvement of antioxidant defense in transgenic plants under water stress, as some other reported NAC TFs, such as SINAC8 [24], SINAC35 [27], GmNAC085 [37], and TaNAC29 [62].

\section{Conclusions}

Our study has elucidated the important role of GmNAC109 in mitigation of drought effects on plants. The improved tolerance of GmNAC109-EX plants was associated with reduced water loss rates and enhanced ROS-scavenging capability of SOD and CAT enzymes. Furthermore, our results provided evidence for the modulation of GmNAC109 action in an ABA-dependent manner. 
Supplementary Materials: The following is available online at http://www.mdpi.com/2218-273X/9/11/714/s1, Table S1: Genes and primers used for RT-qPCR analysis.

Author Contributions: N.C.N. was responsible for data curation, software, resources and writing. X.L.T.H. was responsible for conceptualization, methodology, writing and review. Q.T.N. and N.X.B. were involved in writing. Y.W. was responsible for data curation and resources. N.P.T. was responsible for project administration, conceptualization, writing, review, editing and funding. L.-S.P.T. was responsible for project administration, writing, review and editing.

Funding: This research was funded by the Vietnam National Foundation for Science and Technology Development (NAFOSTED) under grant number "106-NN.02-2015.85".

Conflicts of Interest: The authors declare no conflict of interest.

\section{References}

1. Shao, H.; Wang, H.; Tang, X. NAC transcription factors in plant multiple abiotic stress responses: Progress and prospects. Front. Plant Sci. 2015, 6, 902. [CrossRef] [PubMed]

2. Yadav, N.S.; Shukla, P.S.; Jha, A.; Agarwal, P.K.; Jha, B. The SbSOS1 gene from the extreme halophyte Salicornia brachiata enhances $\mathrm{Na}^{+}$loading in xylem and confers salt tolerance in transgenic tobacco. BMC Plant Biol. 2012, 12, 188. [CrossRef] [PubMed]

3. Cramer, G.R.; Urano, K.; Delrot, S.; Pezzotti, M.; Shinozaki, K. Effects of abiotic stress on plants: A systems biology perspective. BMC Plant Biol. 2011, 11, 163. [CrossRef] [PubMed]

4. Mancosu, N.; Snyder, R.; Kyriakakis, G.; Spano, D. Water scarcity and future challenges for food production. Water 2015, 7, 975-992. [CrossRef]

5. Vurukonda, S.S.K.P.; Vardharajula, S.; Shrivastava, M.; Skz, A. Enhancement of drought stress tolerance in crops by plant growth promoting rhizobacteria. Microbiol. Res. 2016, 184, 13-24. [CrossRef]

6. Farooq, M.; Basra, S.M.A.; Wahid, A.; Cheema, Z.A.; Cheema, M.A.; Khaliq, A. Physiological role of exogenously applied glycinebetaine to improve drought tolerance in fine grain aromatic rice (Oryza sativa L.). J. Agron. Crop Sci. 2008, 194, 325-333. [CrossRef]

7. Osakabe, Y.; Osakabe, K.; Shinozaki, K.; Tran, L.-S.P. Response of plants to water stress. Front. Plant Sci. 2014, 5, 86. [CrossRef]

8. Fang, Y.; Liao, K.; Du, H.; Xu, Y.; Song, H.; Li, X.; Xiong, L. A stress-responsive NAC transcription factor SNAC3 confers heat and drought tolerance through modulation of reactive oxygen species in rice. J. Exp. Bot. 2015, 66, 6803-6817. [CrossRef]

9. Bartels, D.; Sunkar, R. Drought and salt tolerance in plants. Crit. Rev. Plant Sci. 2005, 24, 23-58. [CrossRef]

10. Shinozaki, K.; Yamaguchi-Shinozaki, K. Gene networks involved in drought stress response and tolerance. J. Exp. Bot. 2006, 58, 221-227. [CrossRef]

11. Liu, Q.; Kasuga, M.; Sakuma, Y.; Abe, H.; Miura, S.; Yamaguchi-Shinozaki, K.; Shinozaki, K. Two transcription factors, DREB1 and DREB2, with an EREBP/AP2 DNA binding domain separate two cellular signal transduction pathways in drought- and low-temperature-responsive gene expression, respectively, in Arabidopsis. Plant Cell 1998, 10, 1391-1406. [CrossRef] [PubMed]

12. Hoang, X.L.T.; Nhi, D.N.H.; Thu, N.B.A.; Thao, N.P.; Tran, L.-S.P. Transcription factors and their roles in signal transduction in plants under abiotic stresses. Curr. Genom. 2017, 18, 483-497. [CrossRef]

13. Hu, W.E.I.; Huang, C.; Deng, X.; Zhou, S.; Chen, L.; Li, Y.I.N.; Wang, C.; Ma, Z.; Yuan, Q.; Wang, Y.A.N.; et al. TaASR1, a transcription factor gene in wheat, confers drought stress tolerance in transgenic tobacco. Plant Cell Environ. 2013, 36, 1449-1464. [CrossRef] [PubMed]

14. Thao, N.P.; Thu, N.B.A.; Hoang, X.L.T.; Van Ha, C.; Tran, L.-S.P. Differential expression analysis of a subset of drought-responsive GmNAC genes in two soybean cultivars differing in drought tolerance. Int. J. Mol. Sci. 2013, 14, 23828-23841. [CrossRef]

15. Thu, N.B.A.; Hoang, X.L.T.; Doan, H.; Nguyen, T.-H.; Bui, D.; Thao, N.P.; Phan Tran, L.-S. Differential expression analysis of a subset of $G m N A C$ genes in shoots of two contrasting drought-responsive soybean cultivars DT51 and MTD720 under normal and drought conditions. Mol. Biol. Rep. 2014, 41, 5563-5569. [CrossRef] [PubMed]

16. Nakashima, K.; Ito, Y.; Yamaguchi-Shinozaki, K. Transcriptional regulatory networks in response to abiotic stresses in Arabidopsis and grasses. Plant Physiol. 2009, 149, 88-95. [CrossRef] [PubMed] 
17. Joshi, R.; Wani, S.H.; Singh, B.; Bohra, A.; Dar, Z.A.; Lone, A.A.; Pareek, A.; Singla-Pareek, S.L. Transcription factors and plants response to drought stress: Current understanding and future directions. Front. Plant Sci. 2016, 7, 1029. [CrossRef]

18. Guan, H.; Liu, X.; Niu, F.; Zhao, Q.; Fan, N.; Cao, D.; Meng, D.; He, W.; Guo, B.; Wei, Y.; et al. OoNAC72, a NAC-type Oxytropis ochrocephala transcription factor, conferring enhanced drought and salt stress tolerance in Arabidopsis. Front. Plant Sci. 2019, 10, 890. [CrossRef]

19. Tran, L.; Nakashima, K.; Sakuma, Y.; Simpson, S.; Fujita, Y.; Maruyama, K.; Fujita, M.; Seki, M.; Shinozaki, K.; Yamaguchi-Shinozaki, K. Isolation and functional analysis of Arabidopsis stress-inducible NAC transcription factors that bind to a drought-responsive cis-element in the early responsive to dehydration stress 1 promoter. Plant Cell 2004, 16, 2481-2498. [CrossRef]

20. Quach, T.N.; Tran, L.-S.P.; Valliyodan, B.; Nguyen, H.T.M.; Kumar, R.; Neelakandan, A.K.; Guttikonda, S.K.; Sharp, R.E.; Nguyen, H.T. Functional analysis of water stress-responsive soybean GmNAC003 and GmNAC004 transcription factors in lateral root development in Arabidopsis. PLoS ONE 2014, 9, e84886. [CrossRef]

21. Hoang, X.L.T.; Thu, N.B.A.; Thao, N.P.; Tran, L.-S.P. Transcription factors in abiotic stress responses: Their potentials in crop improvement. In Improvement of Crops in the Era of Climatic Changes, 1st ed.; Ahmad, P., Wani, M.R., Azooz, M.M., Tran, L.-S.P., Eds.; Springer: New York, NY, USA, 2014; Volume 2, pp. 337-366.

22. Puranik, S.; Sahu, P.P.; Srivastava, P.S.; Prasad, M. NAC proteins: Regulation and role in stress tolerance. Trends Plant Sci. 2012, 17, 369-381. [CrossRef] [PubMed]

23. Yu, X.; Peng, H.; Liu, Y.; Zhang, Y.; Shu, Y.; Chen, Q.; Shi, S.; Ma, L.; Ma, H.; Zhang, H. CarNAC2, a novel NAC transcription factor in chickpea (Cicer arietinum $\mathrm{L}$.), is associated with drought-response and various developmental processes in transgenic Arabidopsis. J. Plant Biol. 2014, 57, 55-66. [CrossRef]

24. Wu, D.; Sun, Y.; Wang, H.; Shi, H.; Su, M.; Shan, H.; Li, T.; Li, Q. The SINAC8 gene of the halophyte Suaeda liaotungensis enhances drought and salt stress tolerance in transgenic Arabidopsis thaliana. Gene 2018, 662, 10-20. [CrossRef] [PubMed]

25. Jeong, J.S.; Kim, Y.S.; Redillas, M.C.F.R.; Jang, G.; Jung, H.; Bang, S.W.; Choi, Y.D.; Ha, S.-H.; Reuzeau, C.; Kim, J.-K. OsNAC5 overexpression enlarges root diameter in rice plants leading to enhanced drought tolerance and increased grain yield in the field. Plant Biotechnol. J. 2013, 11, 101-114. [CrossRef] [PubMed]

26. Rahman, H.; Ramanathan, V.; Nallathambi, J.; Duraialagaraja, S.; Muthurajan, R. Over-expression of a NAC 67 transcription factor from finger millet (Eleusine coracana L.) confers tolerance against salinity and drought stress in rice. BMC Biotechnol. 2016, 16 (Suppl. 1), 35. [CrossRef] [PubMed]

27. Wang, G.; Zhang, S.; Ma, X.; Wang, Y.; Kong, F.; Meng, Q. A stress-associated NAC transcription factor (SINAC35) from tomato plays a positive role in biotic and abiotic stresses. Physiol. Plant. 2016, 158, $45-64$. [CrossRef] [PubMed]

28. Thirumalaikumar, V.P.; Devkar, V.; Mehterov, N.; Ali, S.; Ozgur, R.; Turkan, I.; Mueller-Roeber, B.; Balazadeh, S. NAC transcription factor JUNGBRUNNEN1 enhances drought tolerance in tomato. Plant Biotechnol. J. 2018, 16, 354-366. [CrossRef]

29. Tak, H.; Negi, S.; Ganapathi, T.R. Banana NAC transcription factor MusaNAC042 is positively associated with drought and salinity tolerance. Protoplasma 2017, 254, 803-816. [CrossRef]

30. Liu, G.; Li, X.; Jin, S.; Liu, X.; Zhu, L.; Nie, Y.; Zhang, X. Overexpression of rice NAC gene SNAC1 improves drought and salt tolerance by enhancing root development and reducing transpiration rate in transgenic cotton. PLOS ONE 2014, 9, e86895. [CrossRef]

31. Saad, A.S.I.; Li, X.; Li, H.-P.; Huang, T.; Gao, C.-S.; Guo, M.-W.; Cheng, W.; Zhao, G.-Y.; Liao, Y.-C. A rice stress-responsive NAC gene enhances tolerance of transgenic wheat to drought and salt stresses. Plant Sci. 2013, 203-204, 33-40. [CrossRef]

32. Xue, G.-P.; Way, H.M.; Richardson, T.; Drenth, J.; Joyce, P.A.; McIntyre, C.L. Overexpression of TaNAC69 leads to enhanced transcript levels of stress up-regulated genes and dehydration tolerance in bread wheat. Mol. Plant 2011, 4, 697-712. [CrossRef] [PubMed]

33. Le, D.T.; Nishiyama, R.; Watanabe, Y.; Mochida, K.; Yamaguchi-Shinozaki, K.; Shinozaki, K.; Tran, L.-S.P. Genome-wide survey and expression analysis of the plant-specific NAC transcription factor family in soybean during development and dehydration stress. DNA Res. 2011, 18, 263-276. [CrossRef] [PubMed]

34. Hussain, R.M.; Ali, M.; Feng, X.; Li, X. The essence of NAC gene family to the cultivation of drought-resistant soybean (Glycine max L. Merr.) cultivars. BMC Plant Biol. 2017, 17, 55. [CrossRef] [PubMed] 
35. Tran, L.-S.P.; Quach, T.N.; Guttikonda, S.K.; Aldrich, D.L.; Kumar, R.; Neelakandan, A.; Valliyodan, B.; Nguyen, H.T. Molecular characterization of stress-inducible GmNAC genes in soybean. Mol. Genet. Genom. 2009, 281, 647-664. [CrossRef] [PubMed]

36. Nguyen, K.H.; Mostofa, M.G.; Watanabe, Y.; Tran, C.D.; Rahman, M.M.; Tran, L.-S.P. Overexpression of GmNAC085 enhances drought tolerance in Arabidopsis by regulating glutathione biosynthesis, redox balance and glutathione-dependent detoxification of reactive oxygen species and methylglyoxal. Environ. Exp. Bot. 2019, 161, 242-254. [CrossRef]

37. Nguyen, K.H.; Mostofa, M.G.; Li, W.; Van Ha, C.; Watanabe, Y.; Le, D.T.; Thao, N.P.; Tran, L.-S.P. The soybean transcription factor GmNAC085 enhances drought tolerance in Arabidopsis. Environ. Exp. Bot. 2018, 151, 12-20. [CrossRef]

38. So, H.-A.; Lee, J.-H. NAC transcription factors from soybean (Glycine max L.) differentially regulated by abiotic stress. J. Plant Biol. 2019, 62, 147-160. [CrossRef]

39. Hellens, R.P.; Edwards, E.A.; Leyland, N.R.; Bean, S.; Mullineaux, P.M. pGreen: a versatile and flexible binary Ti vector for Agrobacterium-mediated plant transformation. Plant Mol. Biol. 2000, 42, 819-832. [CrossRef]

40. Qin, F.; Sakuma, Y.; Tran, L.-S.P.; Maruyama, K.; Kidokoro, S.; Fujita, Y.; Fujita, M.; Umezawa, T.; Sawano, Y.; Miyazono, K.-I.; et al. DREB2A-interacting proteins function as RING E3 ligases and negatively regulate plant drought stress-responsive gene expression. Plant Cell 2008, 20, 1693-1707. [CrossRef]

41. Clough, S.J.; Bent, A.F. Floral dip: A simplified method for Agrobacterium -mediated transformation of Arabidopsis thaliana. Plant J. 1998, 16, 735-743. [CrossRef]

42. Tizaoui, K.; Kchouk, M.E. Genetic approaches for studying transgene inheritance and genetic recombination in three successive generations of transformed tobacco. Genet. 2012, 35, 640-649. [CrossRef] [PubMed]

43. Murashige, T.; Skoog, F. A revised medium for rapid growth and bio assays with tobacco tissue cultures. Physiol. Plant. 1962, 15, 473-497. [CrossRef]

44. Li, Y.; Varala, K.; Moose, S.P.; Hudson, M.E. The inheritance pattern of $24 \mathrm{nt}$ siRNA clusters in Arabidopsis hybrids is influenced by proximity to transposable elements. PLoS ONE 2012, 7, e47043. [CrossRef] [PubMed]

45. Liu, S.; Jia, F.; Jiao, Z.; Wang, J.; Xia, X.; Yin, W. Ectopic expression of secretory peptide PdEPF3 in Arabidopsis confers drought tolerance with reduced stomatal density. Acta Soc. Bot. Pol. 2019, 88. [CrossRef]

46. Ding, S.; Cai, Z.; Du, H.; Wang, H. Genome-wide analysis of TCP family genes in Zea mays L. identified a role for ZmTCP42 in drought tolerance. Int. J. Mol. Sci. 2019, 20, 2762. [CrossRef]

47. Zhang, L.; Zhang, L.; Xia, C.; Zhao, G.; Jia, J.; Kong, X. The novel wheat transcription factor TaNAC47 enhances multiple abiotic stress tolerances in transgenic plants. Front. Plant Sci. 2016, 6, 1174. [CrossRef]

48. Patterson, B.D.; MacRae, E.A.; Ferguson, I.B. Estimation of hydrogen peroxide in plant extracts using titanium(IV). Anal. Biochem. 1984, 139, 487-492. [CrossRef]

49. Bradford, M.M. A rapid and sensitive method for the quantitation of microgram quantities of protein of protein utlilizing the principle of protein-dye binding. Anal. Biochem. 1976, 72, 248-254. [CrossRef]

50. Giannopolitis, C.N.; Ries, S.K. Superoxide dismutase: I. Occurence in higher plants. Plant Physiol. 1977, 59, 309-314. [CrossRef]

51. Wang, C.-J.; Yang, W.; Wang, C.; Gu, C.; Niu, D.-D.; Liu, H.-X.; Wang, Y.-P.; Guo, J.-H. Induction of drought tolerance in cucumber plants by a consortium of three plant growth-promoting Rhizobacterium strains. PLoS ONE 2012, 7, e52565. [CrossRef]

52. Livak, K.J.; Schmittgen, T.D. Analysis of relative gene expression data using realtime quantitative PCR and the $2^{-\Delta \Delta C t}$ method. Methods 2001, 25, 402-408. [CrossRef] [PubMed]

53. Huang, Y.; Sun, M.-M.; Ye, Q.; Wu, X.-Q.; Wu, W.-H.; Chen, Y.-F. Abscisic acid modulates seed germination via ABA INSENSITIVE5-mediated PHOSPHATE1. Plant Physiol. 2017, 175, 1661-1668. [CrossRef] [PubMed]

54. Ullah, A.; Manghwar, H.; Shaban, M.; Khan, A.H.; Akbar, A.; Ali, U.; Ali, E.; Fahad, S. Phytohormones enhanced drought tolerance in plants: a coping strategy. Environ. Sci. Pollut. Res. Int. 2018, 25, 33103-33118. [CrossRef] [PubMed]

55. Miller, G.A.D.; Suzuki, N.; Ciftci-Yilmaz, S.; Mittler, R.O.N. Reactive oxygen species homeostasis and signalling during drought and salinity stresses. Plant Cell Environ. 2010, 33, 453-467. [CrossRef] [PubMed]

56. Sundaram, S.; Bharti, S.; Khanna-Chopra, R. Superoxide dismutase and abiotic stress tolerance. Physiol. Mol. Biol. Plants 2005, 11, 187-198. 
57. Hossain, M.A.; Bhattacharjee, S.; Armin, S.-M.; Qian, P.; Xin, W.; Li, H.-Y.; Burritt, D.J.; Fujita, M.; Tran, L.-S.P. Hydrogen peroxide priming modulates abiotic oxidative stress tolerance: insights from ROS detoxification and scavenging. Front. Plant Sci. 2015, 6, 420. [CrossRef]

58. Al-Abdallat, A.M.; Ali-Sheikh-Omar, M.A.; Alnemer, L.M. Overexpression of two ATNAC3-related genes improves drought and salt tolerance in tomato (Solanum lycopersicum L.). Plant Cell Tiss. Org. 2015, 120, 989-1001. [CrossRef]

59. An, X.; Liao, Y.; Zhang, J.; Dai, L.; Zhang, N.; Wang, B.; Liu, L.; Peng, D. Overexpression of rice NAC gene SNAC1 in ramie improves drought and salt tolerance. Plant Growth Regul. 2015, 76, 211-223. [CrossRef]

60. Hong, Y.; Zhang, H.; Huang, L.; Li, D.; Song, F. Overexpression of a stress-responsive NAC transcription factor gene ONAC022 improves drought and salt tolerance in rice. Front. Plant Sci. 2016, 7, 4. [CrossRef]

61. Cao, H.; Wang, L.; Nawaz, M.A.; Niu, M.; Sun, J.; Xie, J.; Kong, Q.; Huang, Y.; Cheng, F.; Bie, Z. Ectopic expression of pumpkin NAC transcription factor CmNAC1 improves multiple abiotic stress tolerance in Arabidopsis. Front. Plant Sci. 2017, 8, 2052. [CrossRef]

62. Huang, Q.; Wang, Y.; Li, B.; Chang, J.; Chen, M.; Li, K.; Yang, G.; He, G. TaNAC29, a NAC transcription factor from wheat, enhances salt and drought tolerance in transgenic Arabidopsis. BMC Plant Biol. 2015, 15, 268. [CrossRef] [PubMed]

63. Jia, D.; Jiang, Q.; van Nocker, S.; Gong, X.; Ma, F. An apple (Malus domestica) NAC transcription factor enhances drought tolerance in transgenic apple plant. Plant Physiol. Biochem. 2019, 139, 504-512. [CrossRef] [PubMed]

64. Jin, C.; Li, K.-Q.; Xu, X.-Y.; Zhang, H.-P.; Chen, H.-X.; Chen, Y.-H.; Hao, J.; Wang, Y.; Huang, X.-S.; Zhang, S.-L. A novel NAC transcription factor, PbeNAC1, of Pyrus betulifolia confers cold and drought tolerance via interacting with PbeDREBs and activating the expression of stress-responsive genes. Front. Plant Sci. 2017, 8, 1049. [CrossRef] [PubMed]

65. Lee, D.-K.; Chung, P.J.; Jeong, J.S.; Jang, G.; Bang, S.W.; Jung, H.; Kim, Y.S.; Ha, S.-H.; Choi, Y.D.; Kim, J.-K. The rice OsNAC6 transcription factor orchestrates multiple molecular mechanisms involving root structural adaptions and nicotianamine biosynthesis for drought tolerance. Plant Biotechnol. J. 2017, 15, 754-764. [CrossRef]

66. Mao, H.; Yu, L.; Han, R.; Li, Z.; Liu, H. ZmNAC55, a maize stress-responsive NAC transcription factor, confers drought resistance in transgenic Arabidopsis. Plant Physiol. Biochem. 2016, 105, 55-66. [CrossRef]

67. Huang, L.; Hong, Y.; Zhang, H.; Li, D.; Song, F. Rice NAC transcription factor ONAC095 plays opposite roles in drought and cold stress tolerance. BMC Plant Biol. 2016, 16, 203. [CrossRef]

68. Farber, M.; Attia, Z.; Weiss, D. Cytokinin activity increases stomatal density and transpiration rate in tomato. J. Exp. Bot. 2016, 67, 6351-6362. [CrossRef]

69. Pospíšilová, H.; Jiskrová, E.; Vojta, P.; Mrízová, K.; Kokáš, F.; Čudejková, M.M.; Bergougnoux, V.; Plíhal, O.; Klimešová, J.; Novák, O.; et al. Transgenic barley overexpressing a cytokinin dehydrogenase gene shows greater tolerance to drought stress. New Biotechnol. 2016, 33, 692-705. [CrossRef]

70. Nishiyama, R.; Watanabe, Y.; Fujita, Y.; Le, D.T.; Kojima, M.; Werner, T.; Vankova, R.; Yamaguchi-Shinozaki, K.; Shinozaki, K.; Kakimoto, T.; et al. Analysis of cytokinin mutants and regulation of cytokinin metabolic genes reveals important regulatory roles of cytokinins in drought, salt and abscisic acid responses, and abscisic acid biosynthesis. Plant Cell 2011, 23, 2169-2183. [CrossRef]

71. Duval, M.; Hsieh, T.; Kim, S.; Thomas, T. Molecular characterization of AtNAM: A member of the Arabidopsis NAC domain superfamily. Plant Mol. Biol. 2002, 50, 237-248. [CrossRef]

72. Willemsen, V.; Bauch, M.; Bennett, T.; Campilho, A.; Wolkenfelt, H.; Xu, J.; Haseloff, J.; Scheres, B. The NAC domain transcription factors FEZ and SOMBRERO control the orientation of cell division plane in Arabidopsis root stem cells. Dev. Cell 2008, 15, 913-922. [CrossRef] [PubMed]

73. Kim, H.J.; Nam, H.G.; Lim, P.O. Regulatory network of NAC transcription factors in leaf senescence. Curr. Opin. Plant Biol. 2016, 33, 48-56. [CrossRef] [PubMed]

74. Nuruzzaman, M.; Sharoni, A.M.; Kikuchi, S. Roles of NAC transcription factors in the regulation of biotic and abiotic stress responses in plants. Front. Microbiol. 2013, 4, 248. [CrossRef] [PubMed]

75. Lu, M.; Ying, S.; Zhang, D.-F.; Shi, Y.-S.; Song, Y.-C.; Wang, T.-Y.; Li, Y. A maize stress-responsive NAC transcription factor, ZmSNAC1, confers enhanced tolerance to dehydration in transgenic Arabidopsis. Plant Cell Rep. 2012, 31, 1701-1711. [CrossRef] 
76. Yang, X.; Wang, X.; Ji, L.; Yi, Z.; Fu, C.; Ran, J.; Hu, R.; Zhou, G. Overexpression of a Miscanthus lutarioriparius NAC gene MINAC5 confers enhanced drought and cold tolerance in Arabidopsis. Plant Cell Rep. 2015, 34, 943-958. [CrossRef]

77. Fujita, M.; Fujita, Y.; Maruyama, K.; Seki, M.; Hiratsu, K.; Ohme-Takagi, M.; Tran, L.; Yamaguchi-Shinozaki, K.; Shinozaki, K. A dehydration-induced NAC protein, RD26, is involved in a novel ABA-dependent stress-signaling pathway. Plant J. 2004, 39, 863-876. [CrossRef]

78. Xie, L.-N.; Chen, M.; Min, D.H.; Feng, L.; Xu, Z.-S.; Zhou, Y.-B.; Xu, D.-B.; Li, L.-C.; Ma, Y.-Z.; Zhang, X.-H. The NAC-like transcription factor SiNAC110 in foxtail millet (Setaria italica L.) confers tolerance to drought and high salt stress through an ABA independent signaling pathway. J. Integr. Agric. 2017, 16, 559-571. [CrossRef]

79. Yamaguchi-Shinozaki, K.; Shinozaki, K. Organization of cis-acting regulatory elements in osmotic- and cold-stress-responsive promoters. Trends Plant Sci. 2005, 10, 88-94. [CrossRef]

80. Gómez-Porras, J.L.; Riaño-Pachón, D.M.; Dreyer, I.; Mayer, J.E.; Mueller-Roeber, B. Genome-wide analysis of ABA-responsive elements ABRE and CE3 reveals divergent patterns in Arabidopsis and rice. BMC Genom. 2007, 8, 260. [CrossRef]

81. Narusaka, Y.; Nakashima, K.; Shinwari, Z.K.; Sakuma, Y.; Furihata, T.; Abe, H.; Narusaka, M.; Shinozaki, K.; Yamaguchi-Shinozaki, K. Interaction between two cis-acting elements, ABRE and DRE, in ABA-dependent expression of Arabidopsis rd29A gene in response to dehydration and high-salinity stresses. Plant J. 2003, 34, 137-148. [CrossRef]

82. Yamaguchi-Shinozaki, K.; Shinozaki, K. A novel cis-acting element in an Arabidopsis gene is involved in responsiveness to drought, low-temperature, or high-salt stress. Plant Cell 1994, 6, 251. [PubMed]

83. Daszkowska-Golec, A.; Szarejko, I. Open or close the gate-stomata action under the control of phytohormones in drought stress conditions. Front Plant Sci. 2013, 4, 138. [CrossRef] [PubMed]

84. Outlaw, J.W.H. Integration of cellular and physiological functions of guard cells. Crit. Rev. Plant Sci. 2003, 22, 503-529. [CrossRef]

85. Mostofa, M.G.; Hossain, M.A.; Fujita, M.; Tran, L.-S.P. Physiological and biochemical mechanisms associated with trehalose-induced copper-stress tolerance in rice. Sci. Rep. 2015, 5, 11433. [CrossRef] [PubMed]

86. Noctor, G.; Veljovic-Jovanovic, S.; Driscoll, S.; Novitskaya, L.; Foyer, C.H. Drought and oxidative load in the leaves of $\mathrm{C}_{3}$ plants: a predominant role for photorespiration? Ann. Bot. 2002, 89, 841-850. [CrossRef]

87. Ighodaro, O.; Akinloye, O.A. First line defence antioxidants-superoxide dismutase (SOD), catalase (CAT) and glutathione peroxidase (GPX): Their fundamental role in the entire antioxidant defence grid. Alex. Med. J. 2017, 54. [CrossRef]

88. Rahman, M.M.; Mostofa, M.G.; Rahman, M.A.; Islam, M.R.; Keya, S.S.; Das, A.K.; Miah, M.G.; Kawser, A.Q.M.R.; Ahsan, S.M.; Hashem, A.; et al. Acetic acid: A cost-effective agent for mitigation of seawater-induced salt toxicity in mung bean. Sci. Rep. 2019, 9, 15186. [CrossRef]

89. Harb, A.; Awad, D.; Samarah, N. Gene expression and activity of antioxidant enzymes in barley (Hordeum vulgare L.) under controlled severe drought. J. Plant Interact. 2015, 10, 109-116. [CrossRef]

90. McGrann, G.R.D.; Steed, A.; Burt, C.; Goddard, R.; Lachaux, C.; Bansal, A.; Corbitt, M.; Gorniak, K.; Nicholson, P.; Brown, J.K.M. Contribution of the drought tolerance-related stress-responsive NAC1 transcription factor to resistance of barley to Ramularia leaf spot. Mol. Plant Pathol. 2015, 16, 201-209. [CrossRef]

91. He, L.; Bian, J.; Xu, J.; Yang, K. Novel maize NAC transcriptional repressor ZmNAC071 confers enhanced sensitivity to ABA and osmotic stress by downregulating stress-responsive genes in transgenic Arabidopsis. J. Agric. Food Chem. 2019, 67, 8905-8918. [CrossRef]

(C) 2019 by the authors. Licensee MDPI, Basel, Switzerland. This article is an open access article distributed under the terms and conditions of the Creative Commons Attribution (CC BY) license (http://creativecommons.org/licenses/by/4.0/). 